\title{
Multi-level barriers faced and lessons learned to conduct a randomized controlled trial in patients with diabetes and prediabetes during the COVID-19 pandemic in Brazil
}

Lilian Pinto da Silva ${ }^{1,2 *}$ (1); Mariana Balbi Seixas ${ }^{1,2}$ (1);

Ana Paula Delgado Bomtempo Batalha' (1D; Isabela Coelho Ponciano ${ }^{1}$ (i);

Paul Oh ${ }^{3}$ (1); Gabriela Lima de Melo Ghisi ${ }^{3}$ (1)

\section{How to cite}

Silva LP, Seixas MB, Batalha APDB, Ponciano IC, OhP, Ghisi GLM. Multi-level barriers faced and lessons learned to conduct a randomized controlled trial in patients with diabetes and prediabetes during the COVID-19 pandemic in Brazil. Cardiorespir Physiother Crit Care Rehabil. 2021;1:e42516. https://doi.org/10.4322/2675-9977.cpcr.42516

Coronavirus disease 2019 (COVID-19) is a public health emergency of international concern ${ }^{1}$. In March 2021, the number of confirmed cases worldwide reached 127,818,432, and Brazil ranked second among the countries with the highest number of confirmed cases (more than 12,573,615) and second in number of deaths worldwide ${ }^{2}$. This pandemic is considered the most significant global health crisis of our time due to a high mortality rate associated with severe socioeconomic disruptions, educational institutions' closures, shortages of medical supplies, and barriers for health systems and people, especially those living with chronic diseases such as diabetes ${ }^{3}$.

Diabetes is considered a risk factor for COVID-19 progression and worse prognosis ${ }^{4}$. People living with this health condition are warranted extra precautions ${ }^{4}$, such as having at least a 30-day prescription supply and non-prescription medicines and having their healthcare provider's phone number handy to connect if any concerns arise ${ }^{5}$. Social distancing measures adopted as a strategy for the non-propagation and contamination of the virus caused difficulties for these patients to continue their treatments, which usually involve diabetes self-management education and support, dietary recommendations, and physical exercise ${ }^{6}$. Therefore, these restrictions are leading to metabolic dysregulation and lack of control of coexisting cardiometabolic conditions in these patients ${ }^{7}$.

Faculdade de Fisioterapia juiz de Fora isioterapia, Juiz de Fora, MG, Brasil

2 Universidade Federal de Juiz de Fora UFJF, Hospital Universitário, Unidade de Investigação Cardiovascular e Fisiologia do Exercício, Juiz de Fora, MG, Brasil

${ }^{3}$ University Health Network, Toronto Rehabilitation Institute, Cardiovascular Prevention and Rehabilitation Program, Toronto, ON, Canada

\section{*Corresponding author: Lilian Pinto da Silva \\ Av. Eugênio do Nascimento, s/n, Dom Bosco CEP 36038-330, Juiz de Fora (MG), Brasil Tel.: +55 (32) 2102-3843 ext. 218 Email: lilian.pinto@ufjf.edu.br}

Submitted: January 27, 2021.

Accepted: July 13, 2021.

Study conducted at: Universidade Federal de Juiz de Fora - UFJF, Juiz de Fora, MG, Brasil.

\section{BEYOND COVID-19: THE IMPACT ON SCIENTIFIC RESEARCH}

The complex scenario of the COVID-19 pandemic has negatively impacted the health system and the scientific production ${ }^{8}$, which lays the groundwork for health services progress. Most human health research demands close contact between research team members and participants, which presents a high risk for COVID-19 transmission. Consequently, many research activities were suspended or adapted, such as research meetings, graduate classes, data collections, ongoing research interventions, research laboratory activities, and experimental research involving animals ${ }^{9}$. In addition, research activities directly related to COVID-19 were prioritized to attend this understandable knowledge demand ${ }^{10}$. As a result, research protocols from other areas faced barriers in receiving funding and ethical approvals, delays in scheduled activities ${ }^{11}$, and barriers in publishing results as journals prioritized articles related to the pandemic ${ }^{12}$. Research protocols cannot be suddenly interrupted; therefore, researchers had to seek for adaptations, training, and learning new tools to continue their studies ${ }^{13}$. 


\section{DIABETES COLLEGETM BRAZIL: FIRST-EVER RCT ON COMPREHENSIVE INTERVENTION FOR PORTUGUESE-SPEAKING ADULTS WITH DIABETES}

In this context, significant barriers have emerged in ongoing research activities worldwide, including in the first-ever Brazilian multicenter randomized controlled trial (RCT) entitled "Effects of an Exercise and Lifestyle Education Program for Diabetes and Prediabetes Patients" (NCT03914924), named Diabetes College Brazil Study. This trial received ethics approval from the Research Ethics Committees at the Hospital of Universidade Federal de Juiz de Fora, MG, Brazil (CAAE 77831517.0.2002.5133) and Universidade Federal de Minas Gerais, MG, Brazil (CAAE 77831517.0.1001.5149). Recruitment started January/2020, with participants giving their informed consent before being included in the study. This is a double-blinded RCT with two parallel arms: Exercise and Lifestyle Education program (ExLE; 12 weeks of educational and exercise intervention) and Exercise program (Ex; 12 weeks of exercise intervention only) for adults with diabetes and prediabetes. Participants attended 16 supervised and individually-prescribed one-hour exercise sessions and received counseling for unsupervised physical exercise to reach a goal of 150 minutes of aerobic exercise per week and muscle strength exercises two times a week. Participants in the ExLE program also received 18 thirtyminute educational classes based on the Diabetes College ${ }^{\mathrm{TM}}$, an evidence-based and theoretically-informed comprehensive diabetes educational program available globally ${ }^{14}$. This program was translated and culturally adapted for use in Brazi $l^{15}$. The topics delivered in these classes included diabetes treatment and complications, eating health, well-being, and exercise. The purpose of this RCT was to investigate the effects of this comprehensive intervention in functional capacity, disease-related knowledge, health behaviors (physical activity, diet, and medication adherence), cardiometabolic health parameters (glycated hemoglobin, body weight, and cardiac autonomic control), health literacy, exercise self-efficacy, quality of life, and program satisfaction and adherence.

\section{ADAPTING THE PROJECT TO THE NEW NORMAL IMPOSED BY THE PANDEMIC}

Conducting an RCT in low- and middle-income countries imposes a series of challenges to the research team. It involves a robust design that demands financial support, staff training, and accurate planning and execution ${ }^{16}$. In the current pandemic scenario, these challenges increased by the placement of the new normal. Two months after the first participants were enrolled on the Diabetes College Brazil Study all on-site activities were suspended due to the COVID-19 pandemic ${ }^{1}$. This unexpected situation imposed on the research team a need for an immediate response and challenging decisions. The research team decided to switch the delivery of RCT interventions from in-person to virtual to ensure the continuity of the project, aligning with the need to follow the protocol (learning ${ }^{17}$ and physical exercise ${ }^{18}$ maintenance). Specifically, the educational intervention was changed from in-person lectures and peer- support discussions to recorded video lectures. This change was strategically planned, with videos recorded and uploaded on a video hosting platform and links shared with the ExLE program participants. Supervised exercise was replaced with non-supervised sessions supported by exercise videos. In addition, all participants were contacted once a week by phone following a structured script (i.e., questions concerning the educational contents of the videos, exercise routine, and clinical conditions). Questionnaire packages and all necessary equipment were delivered to participants for post-intervention assessments. A research team member supervised completing questionnaires and the walking test (functional capacity evaluation) virtually by phone or video call. Moreover, the research team developed manuals for each outcome assessment to help participants understand the process.

Thirty-seven patients (18.5\% of the target sample) were enrolled in the RCT in March/2020. Participants were in different stages of the interventions when the restrictions were taken into place: 20 subjects received 10 weeks $(83 \%)$ of the intervention delivered virtually, and 17 subjects received only 4 weeks (33\%) of the intervention in this new delivery model. Thirty-three of the participants enrolled (89\%) concluded the 12-week intervention as originally planned; of these, $17(51.5 \%)$ participated in the ExLE program and 16 (48.5\%) in the Ex program. Table 1 shows the clinical characteristics of participants who started and completed the intervention and the intervention delivery model (in-person and virtually).

\section{A SOCIO-ECOLOGICAL APPROACH OF BARRIERS PERCEIVED BY THE RESEARCH TEAM AND PARTICIPANTS}

Barriers perceived by the research team were shared in weekly online research team meetings. These barriers are illustrated in Figure 1, organized according to the socioecological model (SEM) $)^{19}$. This theory has been shown to

Table 1. Participants' demographic and clinical characteristics and intervention delivery mode.

\begin{tabular}{|c|c|c|c|c|}
\hline & \multirow{2}{*}{\multicolumn{2}{|c|}{$\begin{array}{l}\text { Start of the intervention } \\
\qquad(\mathrm{n}=37)\end{array}$}} & \multirow{2}{*}{\multicolumn{2}{|c|}{$\begin{array}{c}\begin{array}{c}\text { Completion of the } \\
\text { intervention }\end{array} \\
(n=33)\end{array}$}} \\
\hline & & & & \\
\hline & $\begin{array}{c}\text { ExLE } \\
(n=18)\end{array}$ & $\begin{array}{c}\text { Ex } \\
(n=19)\end{array}$ & $\begin{array}{c}\text { ExLE } \\
(n=17)\end{array}$ & $\begin{array}{c}\text { Ex } \\
(n=16)\end{array}$ \\
\hline \multicolumn{5}{|l|}{ Sex } \\
\hline Female - n (\%) & $10(56 \%)$ & $10(53 \%)$ & $9(53 \%)$ & $7(44 \%)$ \\
\hline Male - n (\%) & $8(44 \%)$ & $9(47 \%)$ & $8(47 \%)$ & $9(56 \%)$ \\
\hline Age (years) & $58 \pm 9.1^{\mathrm{a}}$ & $59 \pm 11.2^{\mathrm{a}}$ & $58 \pm 9.4^{\mathrm{a}}$ & $61 \pm 7.0^{\mathrm{a}}$ \\
\hline \multicolumn{5}{|l|}{ Diabetes type } \\
\hline Type 1 - n (\%) & $4(22 \%)$ & $3(16 \%)$ & $4(23 \%)$ & $2(12 \%)$ \\
\hline Type 2 - n (\%) & $13(72 \%)$ & $12(63 \%)$ & $12(71 \%)$ & $11(69 \%)$ \\
\hline Prediabetes - n (\%) & $1(6 \%)$ & $4(21 \%)$ & $1(6 \%)$ & $3(19 \%)$ \\
\hline \multicolumn{5}{|c|}{ Intervention delivery mode } \\
\hline $\begin{array}{l}\text { Predominantly } \\
\text { in-person - n (\%) }\end{array}$ & $8(44 \%)$ & $9(47 \%)$ & $7(41 \%)$ & $8(50 \%)$ \\
\hline $\begin{array}{l}\text { Predominantly } \\
\text { virtual- } \mathrm{n}(\%)\end{array}$ & $10(56 \%)$ & $10(53 \%)$ & $10(59 \%)$ & $8(50 \%)$ \\
\hline
\end{tabular}

${ }^{\mathrm{a} M e a n} \pm$ standard deviation 

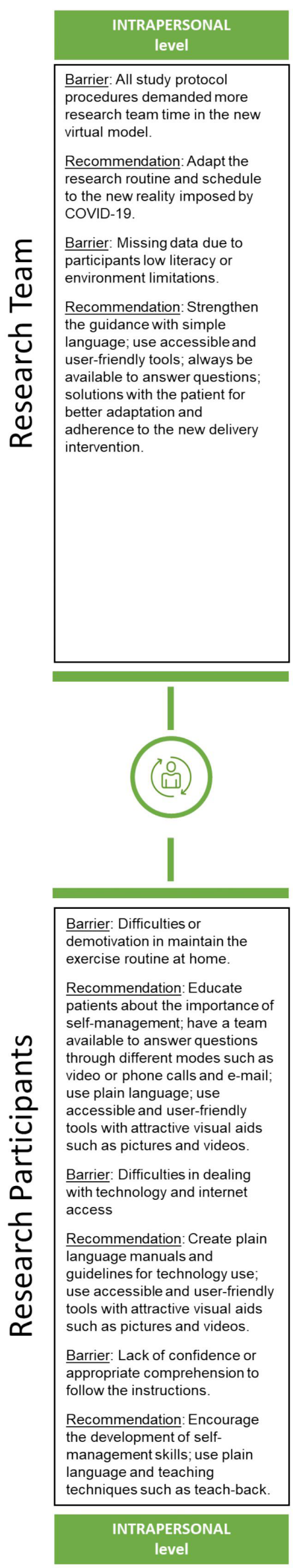
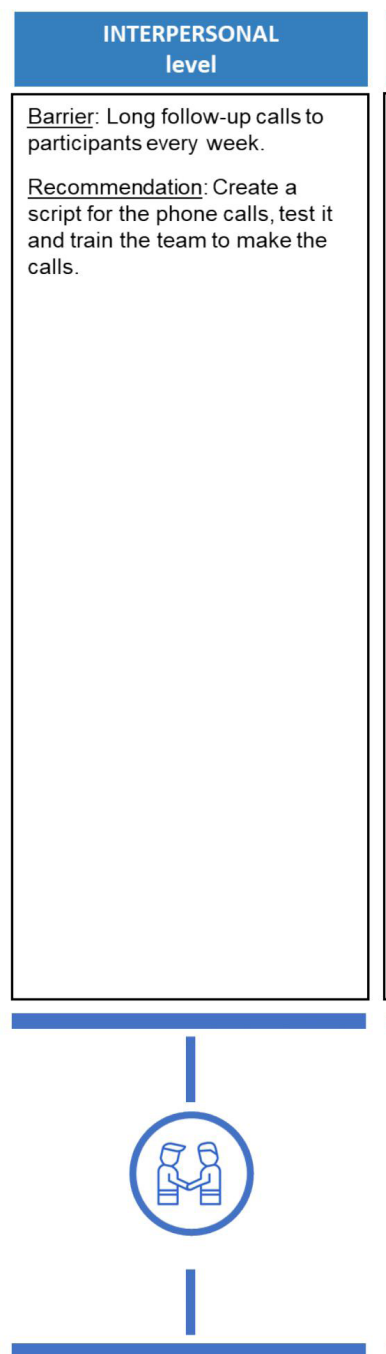

Barrier: Difficult in filling out the exercise diaries and

sending them to the research team.

Recommendation: Use plain language and teaching techniques to explain to participants what they have to do; search for other ways to receive this information from participants.
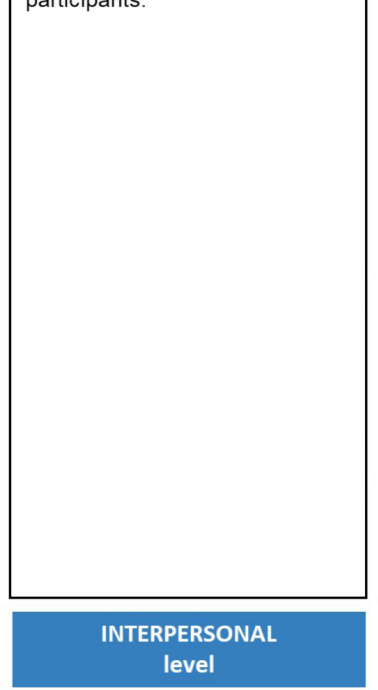


No identified barriers in this level by the research team

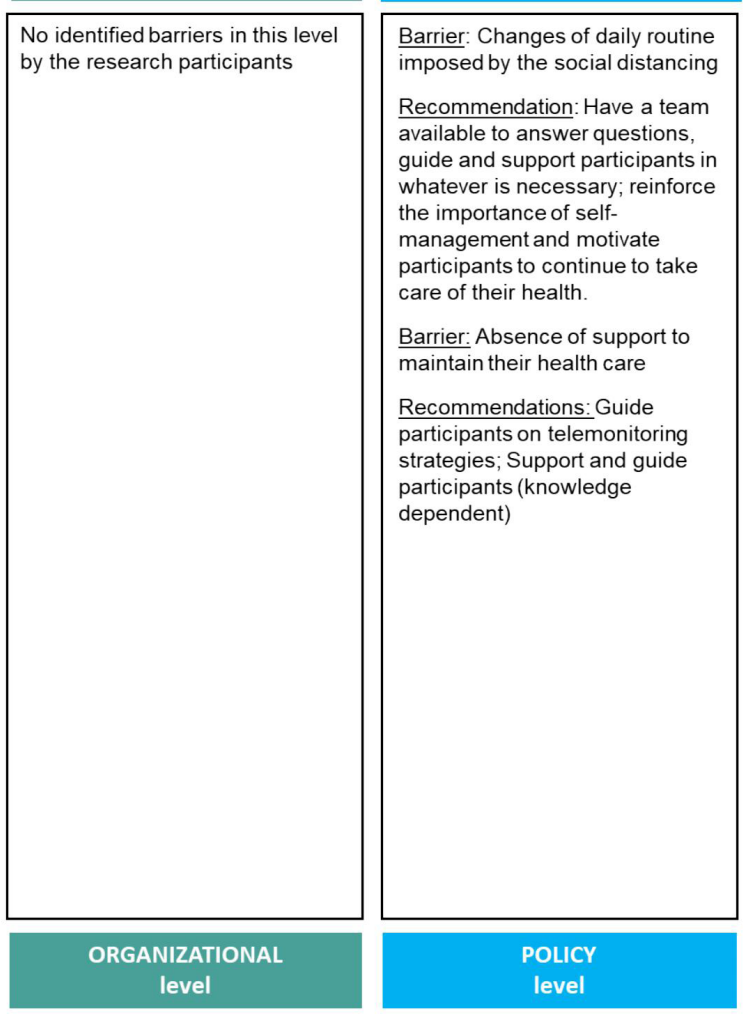

Figure 1. Barriers faced by the research team and participants concerning the program's virtual delivery and assessments. 
effectively encompass a broad perspective on the relations between people and their environment and inform knowledgetranslation initiatives, including research, to close the equity gap $^{20}$. The researchers also discussed the adaptations needed in the research protocol due to the pandemic. They made these updates on the work performed during the week, including the facilitators and barriers faced for the implementation of the protocol. Participants' perceived barriers were also organized following SEM (Figure 1) and obtained from weekly follow-up calls. In these calls, participants shared their perceptions about changes and adaptations to the original research protocol and reported difficulties faced and goals achieved. Recommendations for each barrier are also illustrated in Figure 1.

\section{LEARNING DURING CHALLENGING TIMES}

Despite barriers described, participants showed persistence and acceptance of all changes made in such a delicate time. The research team stood up to difficulties and fears inherent to this unique moment and showed that it was possible to continue the research activities virtually, against all barriers. As a result, there were valuable lessons learned, especially concerning technology, education interventions delivery, and RCT data collection. The implementation of virtual interventions highlighted technology difficulties that participants faced, which has been previously reported in another study ${ }^{18}$. Unlike the variables assessed by questionnaires, it was not feasible to obtain a proper virtual assessment of variables collected by walking test and heartbeat monitoring. In addition, it is not possible to assure these first results reveal the real effects of interventions since current limitations and stress imposed on the participants can influence their outcomes. We have learned that the current global situation asks for additional phases in the Diabetes College Brazil Study to validate the results, including a feasibility RCT study with a virtual intervention ${ }^{21}$.

Although several studies have reported the effectiveness of virtual interventions in cardiovascular diseases ${ }^{22,23}$, none of them has assessed a remote, structured, evidence-based model in a low- and middle-income country. By the imposed changes in our research protocol, new and relevant research questions emerged, including the perception, barriers, and acceptance of diabetes and prediabetes patients in receiving virtual care and motivation and adherence to this intervention mode.

\section{EXPECTATIONS ABOUT THE FUTURE}

Until further notice, the recruitment of new study participants is suspended. The participants who concluded the program and the post-intervention assessment were virtually contacted monthly by the research team as part of the sixmonth follow-up included in the study protocol. Additionally, the research team is looking for viable ways to resume the $\mathrm{RCT}$, ensuring the safety of participants as well as their own.

Although multi-level barriers were perceived both by the research team and participants, they have learned how to overcome these barriers by adapting the study protocol to deliver the intervention virtually, remaining physically active, and following the proposed program. Overall, the main learning of running an RCT in one of the most affected countries during a global pandemic was the use of technology to deliver healthcare to people with diabetes and prediabetes in a low-to middle income setting. This lesson learned can be replicable to other situations such as people living in rural or low-mobility areas. More research is needed to identify the feasibility of delivering education and exercise interventions virtually on a large-scale.

\section{Funding}

This study was financed in part by the Coordenação de Aperfeiçoamento de Pessoal de Nível Superior - Brasil (CAPES) [Finance Code 001] and Universidade Federal de Juiz de Fora.

\section{Conflict of interest}

None.

\section{References}

1. World Health Organization - WHO [Internet]. 2021 [cited 2021 Mar 30]. Available from: https://www.who.int/

2. Coronavirus Resource Center Johns Hopkins. COVID-19 map [Internet]. 2021 [cited 2021 Mar 30]. Available from: https:// coronavirus.jhu.edu/map.html

3. Chu IY, Alam P, Larson HJ, Lin L. Social consequences of mass quarantine during epidemics: a systematic review with implications for the COVID-19 response. J Travel Med. 2020;27(7):taaa192. http:// dx.doi.org/10.1093/jtm/taaa192. PMid:33051660.

4. Guo W, Li M, Dong Y, Zhou H, Zhang Z, Tian C, et al. Diabetes is a risk factor for the progression and prognosis of COVID-19. Diabetes Metab Res Rev. 2020;36(7):e3319. http://dx.doi.org/10.1002/dmrr.3319. PMid:32233013.

5. Centers for Disease Control and Prevention-CDC. Certas condições médicas e risco de doença grave por COVID-19 [Internet]. 2021 [cited 2021 Mar 30]. Available from: https:/www.cdc.gov/coronavirus/2019ncov/need-extra-precautions/people-with-medical-conditions.html

6. Powers MA, Bardsley J, Cypress M, Duker P, Funnell MM, Fischl $\mathrm{AH}$, et al. Diabetes Self-management education and support in type 2 diabetes: a joint position statement of the American Diabetes Association, the American Association of Diabetes Educators, and the Academy of Nutrition and Dietetics. J Acad Nutr Diet. 2015;115(8):1323-34. http:// dx.doi.org/10.1016/j.jand.2015.05.012. PMid:26054423.

7. Angelidi AM, Belanger MJ, Mantzoros CS. Commentary: COVID-19 and diabetes mellitus: What we know, how our patients should be treated now, and what should happen next. Metabolism. 2020;107:154245. http://dx.doi.org/10.1016/j.metabol.2020.154245. PMid:32320742.

8. Mourad M, Bousleiman S, Wapner R, Gyamfi-Bannerman C. Conducting research during the COVID-19 pandemic. Semin Perinatol. 2020;44(7):151287. http://dx.doi.org/10.1016/j.semperi.2020.151287. PMid:32807490.

9. Kroenke K, Bair MJ, Sachs GA. Continuing research during a crisis. J Gen Intern Med. 2021;36(4):1086-8. http://dx.doi.org/10.1007/s11606021-06636-5. PMid:33559063.

10. Singh $P$. The research community must meet the coronavirus disease 2019 challenge. Indian J Med Res. 2020;151(2-3):116-7. PMid:32270770.

11. Townsend E, Nielsen E, Allister R, Cassidy SA. Key ethical questions for research during the COVID-19 pandemic. Lancet Psychiatry. 2020;7(5):381-3. http://dx.doi.org/10.1016/S2215-0366(20)30150-4. PMid:32353264. 
12. Horbach SPJM. Pandemic publishing: medical journals drastically speed up their publication process for Covid-19. bioRxiv. http://dx.doi. org/10.1101/2020.04.18.045963.

13. Fleming TR, Labriola D, Wittes J. Conducting clinical research during the COVID-19 pandemic: protecting scientific integrity. JAMA. 2020;324(1):33-4. http://dx.doi.org/10.1001/jama.2020.9286. PMid:32463422.

14. Ghisi GLM, Aultman C, Konidis R, Foster E, Sandison N, Alavinia $\mathrm{M}$, et al. Development and validation of the DiAbeTes Education Questionnaire (DATE-Q) to measure knowledge among diabetes and prediabetes patients attending cardiac rehabilitation programs. J Cardiopulm Rehabil Prev. 2021;41(4):224-9. http://dx.doi.org/10.1097/ HCR.0000000000000546. PMid:33512977.

15. Ghisi GLM, Seixas MB, Pereira DS, Cisneros LL, Ezequiel DGA, Aultman C, et al. Patient education program for Brazilians living with diabetes and prediabetes: findings from a development study. BMC Public Health. 2021 Jun 26;21(1):1236. http://dx.doi.org/10.1186/ s12889-021-11300-y. PMid:34174860.

16. Bonsu JM, Frasso R, Curry AE. Lessons from the field: the conduct of randomized controlled trials in Botswana. Trials. 2017;18(1):503 http://dx.doi.org/10.1186/s13063-017-2237-4. PMid:29078791.

17. Contreras F, Sanchez M, Martinez MS, Castillo MC, Mindiola A, Bermudez V, et al. Management and Education in Patients with Diabetes Mellitus. Med Clin Rev. 2017;3(2):7. http://dx.doi. org/10.21767/2471-299X.1000049.
18. Peçanha T, Goessler KF, Roschel H, Gualano B. Social isolation during the COVID-19 pandemic can increase physical inactivity and the global burden of cardiovascular disease. Am J Physiol Heart Circ Physiol. 2020;318(6):H1441-6. http://dx.doi.org/10.1152/ajpheart.00268.2020. PMid:32412779.

19. Stokols D. Translating social ecological theory into guidelines for community health promotion. Am J Health Promot. 1996;10(4):28298. http://dx.doi.org/10.4278/0890-1171-10.4.282. PMid:10159709.

20. McLaren L, Hawe P. Ecological perspectives in health research. J Epidemiol Community Health. 2005;59(1):6-14. http://dx.doi. org/10.1136/jech.2003.018044. PMid:15598720.

21. Lumeng JC, Chavous TM, Lok AS, Sen S, Wigginton NS, Cunningham RM. A risk-benefit framework for human research during the COVID-19 pandemic. Proc Natl Acad Sci USA. 2020;117(45):2774953. http://dx.doi.org/10.1073/pnas.2020507117. PMid:33087558.

22. Babu AS, Arena R, Ozemek C, Lavie CJ. COVID-19: a time for alternate models in cardiac rehabilitation to take centre stage. Can J Cardiol. 2020;36(6):792-4. http://dx.doi.org/10.1016/j. cjca.2020.04.023. PMid:32344000.

23. Clark RA, Conway A, Poulsen V, Keech W, Tirimacco R, Tideman P. Alternative models of cardiac rehabilitation: a systematic review. Eur J Prev Cardiol. 2015;22(1):35-74. http://dx.doi. org/10.1177/2047487313501093. PMid:23943649. 


\section{Author contributions}

LPS, PO and GLMG: Conception of the study. LPS, MBS, GLMG: Data interpretation; MBS, APDBB and ICP: Data acquisition, supervision and analysis; LPS, MBS, APDBB, ICP, GLMG: Writing, revising and editing the manuscript.

\section{Author information}

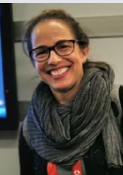

Lilian Pinto da Silva

Graduated in Physiotherapy, Universidade Estadual Paulista (UNESP), Campus de Presidente Prudente, Brazil; PhD in Biomedical Engineering, Universidade Federal do Rio de Janeiro (UFRJ), Brazil; Associate Professor, Faculty of Physiotherapy, Universidade

Federal de Juiz de Fora (UFJF), Brazil.

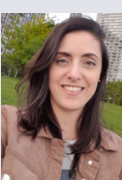

Mariana Balbi Seixas

Graduated in Physiotherapy, Universidade Federal de Juiz de Fora (UFJF), Brazil: MSc in Physical Education, Universidade Federal de Juiz de Fora (UFJF), Brazil; Physiotherapist, Faculty of Physiotherapy, Universidade Federal de Juiz de Fora (UFJF), Brazil.

\section{Ana Paula Delgado Bomtempo Batalha}

Graduated in Physiotherapy, Universidade Federal de Juiz de Fora (UFJF), Brazil; MSc in Rehabilitation and Physical-Functional Performance Sciences, Universidade Federal de Juiz de Fora (UFJF), Brazil; Post graduated in women's health, Unylya Faculty, Brazil.

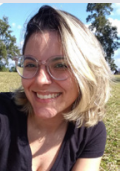

Isabela Coelho Ponciano

Graduated in Physiotherapy, Universidade Federal de Juiz de Fora (UFJF), Brazil; MSc in Rehabilitation and Physical-Functional Performance Sciences, Universidade Federal de Juiz de Fora (UFJF), Brazil; Clinical physiotherapist with emphasis on adult and elderly health.



Paul Oh

Medical Director and GoodLife Fitness Chair, Cardiovascular Prevention and Rehabilitation Program; Associate Professor of Medicine, University of Toronto; He has led or participated in provincial and national advisory and guidelines committees around heart health and policies.

\section{Gabriela Lima De Melo Ghisi}

Scientific associate at the Cardiovascular Prevention and Rehabilitation Program, University of Toronto, Canada; She has 5 years of clinical experience in the cardiac rehabilitation (CR) setting in Brazil and 12 years of research experience in CR in Canada; Dr. Ghisi's program of research focuses on patient education in CR. 